\title{
a-Mangosteen as An Oxidative Inhibitor in Hepatocellular Carcinoma
}

\author{
Harliansyah $^{1}$, Nunung Ainur Rahmah ${ }^{2}$, Kuslestari $^{3}$ \\ ${ }^{1}$ Department of Biochemistry, Faculty of Medicine, University of YARSI \\ ${ }^{2}$ Department of Pathology Anatomy, Faculty of Medicine, University of YARSI \\ ${ }^{3}$ Department of Histology, Faculty of Medicine, University of YARSI
}

\begin{abstract}
Hepatocellular carcinoma ( $\mathrm{HCC})$ is the most common primary malignancy of the liver and the second leading cause of cancer mortality worldwide. Many strategies to discover molecular-based therapy are currently being implemented to overcome the resistance in $\mathrm{HCC}$ treatment. Cancer research is more targeted at molecular level of natural ingredients treatment as chemoprevention to reduce carcinogenesis risk. One of the natural compounds that serve as chemopreventive agent is mangosteen. a-Mangosteen, a xanthone commonly found in the fruit hull of Garcinia mangostana Linn, possess as an antioxidant. This study aims to determine the levels of reactive oxygen species (ROS), malondialdehyde (MDA), and protein carbonyl (PC) as the biomarkers of oxidative stress on untreated HepG2 cells compared to a-mangosteen-treated HepG2 cells. The results indicated that a-mangosteen has a cytotoxic effect on HepG2 cells with $\mathrm{IC}_{50}=242.58 \mu \mathrm{g} / \mathrm{mL}$ and reduced ROS level $23.15 \pm 4.29 \%$ at $200 \mu \mathrm{g} / \mathrm{mL}$. The MDA level of HepG2 cells was not significantly higher than on WRL-68 by $7.6 \%, 17.93 \%, 28.8 \%, 35.32 \%$, and $61.95 \%$ at $100,200,500,800$, and 1000 $\mu \mathrm{g} / \mathrm{mL}$ respectively. a-Mangosteen at 100 and $200 \mu \mathrm{g} / \mathrm{mL}$ reduced protein carbonyl by 76.24 and $79.84 \%$ in HepG2 cells line while compared to normal liver cells line (WRL-68) significantly $(P<0.05)$. In conclusion, a-mangosteen reduced levels of ROS, MDA and PC. Therefore, a-mangosteen is a potential anti-cancer agent through oxidative stress inhibition.
\end{abstract}

Keyword: free radical, HepG2 cells, a-mangosteen, oxidative stress.

\section{INTRODUCTION}

Hepatocellular carcinoma (HCC), one of the liver cancers, is the most common malignant liver and the second leading cause of cancer mortality worldwide. According to US surveillance, epidemiology, and results (SEER) database program, HCC accounts for $65 \%$ of all cases of liver cancers. The incidence rate of HCC increased from 1.4/100,000 cases/year between 1976-1980 to $6.2 / 100,000$ cases reported in 2011 and predominant in Asian countries (Ghouri, et al., 2017). A study in Indonesia revealed that the mortality rate of patients with $\mathrm{HCC}$ in Cipto Mangunkusumo National General Hospital was 48.2\% (Jasirwan, et al., 2020). Chronic infection with hepatitis $\mathrm{B}$ and $\mathrm{C}$ virus is one of the high-risk conditions leading to HCC. As no obvious sign or symptom, the tumor is

Submitted: June 13, 2021

Revised: September 21, 2021

Accepted: October 4, 2021

*Corresponding author: harliansyah.hanif@yarsi.ac.id 
hard to diagnose at first and able to detect after the tumor become large. The treatment and survival rate of patients-diagnosed with HCC is doubtful (Gani, 2017). Also, the efficacy of treatment was limited and needed more understanding of patient who could obtain the benefit of treatment. Resistance also occurs in first-line or single drug. The altered pathways within cells is fundamental caused of tumorigenesis, the metastatic process, and stem cell properties disturbance (Le Grazie, et al., 2017).

Many strategies for selecting the molecularbased therapy are currently being implemented to overcome the resistance in HCC treatment. Nowadays, cancer research is targeted to potential natural ingredients toward molecular mechanism as chemoprevention agent in order to reduce carcinogenesis risk. Chemoprevention is a rapidly developing focus of oncology that focuses on the cancer-preventive strategy by natural or synthetic interventions (Manimekalai, et al., 2016).

Cellular macromolecule disruption, such as DNA, proteins, lipids, and carbohydrate is a result of oxidative modification induced by oxidative stress (Liguori, et al., 2018). Prolongation of the disruption could increase the risk of several chronic diseases, such as cancer, autoimmune diseases, cardiovascular diseases, neurodegenerative diseases, mental disorders, and skin aging. For minimizing the risk, antioxidants are needed which are compounds that could stabilize free radicals by hydrogen atoms donation mechanism, lowdensity lipoprotein (LDL) oxidation inhibition, and metal ions chelation. The stabilization of free radicals by antioxidants could prevent and repair DNA damage (Elmund, 2020). The study of chemoprevention mechanism is often associated with antioxidant properties, redox, and antiinflammatory molecules contained in natural active ingredients (Tan, et al., 2011; Bose, et al., 2020). One of the naturals compounds that possesses as chemopreventive agent is mangosteen. Mangosteen (Garcinia mangostana Linn) family of Guttiferae, is one of the fruits that widely grows in Southeast Asia. The fruit flesh is soft and white which also contain high sugar and low protein. The oil of mangosteen seeds contain essential fatty acids such as linoleic (1.3\%), palmitic (49.5\%), and oleic (34\%) (Quan, et al., 2012). Previous studies reported Garcinia mangosteen as a potent source of natural antioxidants which are a great therapeutic agent by preventing or slowing down the progress of aging, age-associated oxidative stress, and related degenerative diseases. Mangosteen extracts, products, and isolated compounds showed to rise antioxidant levels through in vivo studies by either increasing antioxidant enzymes (such as SOD, CAT, GPx, and GSH) or decreasing oxidative stress markers (such as MDA level) (Manimekalai, et al., 2016). However, there is few information corelated with reactive oxygen species (ROS), malondialdehyde (MDA), and protein carbonyl (PC) carbonyl proteins within HCC. This study aims to determine the levels of ROS, MDA, and PC as oxidative stress biomarkers on untreated HepG2 cells compared to $\alpha$-mangosteen-treated HepG2. The results can be used as fundamental literature for further research.

\section{MATERIAL AND METHODS}

\section{Material}

The HepG2 human hepatoblastoma cancer cell lines and WRL-68 human hepatocyte normal cell lines were purchased from ATCC (Rockville, MD, USA). Eagle's minimum essential medium (EMEM) (Gibco, New York, USA) was supplemented with $10 \%$ fetal bovine serum (Biowest, Riverside, USA), $5 \%$ amphotericin, and 5\% penicillin-streptomycin (Biosciences, San Jose, USA). $\alpha$-Mangosteen was purchased from Chromadex (Irvin, CA) with 95\% purity. The MTT kit was obtained from Promega (Madison, USA). The DCFDA-Cellular Reactive Oxygen Species kit was obtained from the Abcam Mito Sciences catalog no 113851. 


\section{Cell Culture}

The HepG2 and WRL-68 cells were cultured in a tissue flask containing EMEM complex growth medium to obtain a confluency of $70-80 \%$. After the cells were harvested, the cells were counted using a haemocytometer. Cells were used for about $1 \times 10^{6}$ cells/a well, then treated $\alpha$-mangosteen which had dissolved in DMSO.

\section{Cytotoxicity Assay}

The cytotoxicity assay based on colorimetric principle under MTT Assay. Cells $\left(5 \times 10^{3}\right.$ per well) were plated in 96 well-plates and treated for $24 \mathrm{~h}$ with $\alpha$-mangosteen concentrations of $0,100,200$, 500, 800, and $1000 \mu \mathrm{g} / \mathrm{mL}$. Additionally, $0.1 \%$ DMSO was also used as a control. Cell viability analysis was done using MTT assay (Promega, Madison, WI, USA) according to manufacturer's instruction. Absorbance was measured at $570 \mathrm{~nm}$ using a 96-well plate reader. Cytotoxic analysis of $\alpha$-mangosteen samples on cells was carried out by calculating a $50 \%$ cell inhibition concentration $\left(\mathrm{IC}_{50}\right)$ based on triplicate data.

\section{Preparation of Reactive Oxygen Species (ROS), Malondialdehyde (MDA), Protein Carbonyl Analysis}

Prior the analysis, cells $\left(1 \times 10^{8}\right)$ treated with $\alpha$-mangosteen, then washed three times using $200 \mu \mathrm{L}$ of cold $50 \mathrm{mM}$ phosphate buffer solution, $\mathrm{pH}$ 7.0. Cell suspension was centrifuged at a speed of $600 \mathrm{rpm}$ for 10 minutes at $40^{\circ} \mathrm{C}$ and the supernatants were discarded. Then the cell pellets were being suspended in a cold $50 \mathrm{mM}$ phosphate buffer solution, pH 7.0 (1:2). The cell homogenate was subsequently solved using a sonicator for 2 minutes at $40^{\circ} \mathrm{C}$. Furthermore, the suspension of this cell was centrifuged again at a speed of 10,000 rpm for 10 minutes at $40^{\circ} \mathrm{C}$. The supernatant was collected and stored in a cold freezer $-20^{\circ} \mathrm{C}$ to be used for the analysis of ROS, MDA, and protein carbonyl respectively.

\section{Cellular Reactive Oxygen Species (ROS) Analysis}

Examination of ROS activity was carried out by ELISA following protocol of Abcam Mito Sciences catalogs No. 113851. After 2,7-dichlorofluorescein diacetate (DCFDA) reagent diffused into the cell, the DCFDA will be deacetylated by cellular esterase enzyme. Then it became a non-fluorescent compound and immediately oxidized by ROS from to 2,7-dichlorofluorescein (DCF) compounds which was detected in fluorescent spectroscopy on a plate reader at excitation/emission of $485 \mathrm{~nm} / 535$ nm. ROS levels of HepG2 and WRL-68 cells were treated by $\alpha$-mangosteen at a concentration of 5,10 , $50,100,200,500$, and $1000 \mu \mathrm{g} / \mathrm{mL}$.

\section{Measuring of Malondialdehyde (MDA) Levels}

The formation of MDA as a result of lipid peroxidation reactions can be analyzed by detecting red mixture through the thiobarbiturate (TBA) form under spectrophotometry The standard curve is determined through compound 1.1.3.3-tetraetoxy propane (TTHP), where $100 \mu \mathrm{M}$ TTHP solution was dissolved with distilled water to exactly contain 1 , $2,5,10$, and $20 \mu \mathrm{M}$ in each solutions. Subsequently, $1.5 \mathrm{~mL}$ of a $0.8 \%$ solution of thiobarbituric acid (in $20 \%$ acetic acid) was added. All the tubes were then put into a boiling water bath for 60 minutes. Then let it cold for 10 minutes. After that, every $1.5 \mathrm{~mL}$ from each tube transferred into the cuvette and read at a wavelength of $532 \mathrm{~nm}$ under spectrophotometry.

\section{Protein Carbonyl (PC) Measurement}

The PC measurement indicated of protein oxidation due to high levels of ROS within cells. The presence of redox cations such as Fe (II) or $\mathrm{Cu}$ (II) can be bound to cell proteins which then react with free radicals (hydrogen peroxide) to change the amine groups of side chains of amino acids (Lys, Arg, Pro, or His) to form carbonyl. This carbonyl reaction with 2.4 dinitrophenyl hydrazine 
(DNPH) reagent will form the Schiff base which then forms hydrazone and can be measured by spectrophotometry at wavelengths of 360-385 nm. Supernatant were diluted 1 per 4 with saline buffer solution pH 7.4 and centrifuged at 14,000 rpm for 10 minutes. The dissolved protein was then stored within a solution of $20 \%$ trichloroacetic acid (TCA) and centrifuged again for 5 minutes. Then added 10 $\mathrm{mM}$ DNPH in $2 \mathrm{~N} \mathrm{HCl}$ and left for $1 \mathrm{~h}$ in a dark room with shaking every 10 minutes. This mixture was added with $6 \mathrm{M}$ guanidine hydrochloride and given $2 \mathrm{~N} \mathrm{HCl}$ left for 15 minutes at $37^{\circ} \mathrm{C}$ using the vortex. The PC content was determined by spectrophotometrically at a wavelength of $366 \mathrm{~nm}$ with a molar coefficient of $22,000 / \mathrm{MCm}^{-1}$.

\section{Statistical Analysis}

The results are illustrated as mean \pm standard deviation from three experiments where each experiment was triplicate. The statistical data is established by Student t-test with the degree of toughness $p<0.05$.

\section{RESULT}

\section{a-Mangosteen Cytotoxicity Assay}

Under cytotoxicity assay, the integrity of mitochondrial cells could be seen as methylene blue form in result of reduction by dehydrogenase enzyme during cell metabolism under MTT Assay. The more rapid of blue color forming indicates the ability of cells to metabolize well. Treatment with $\alpha$-mangosteen within cell growth medium also influenced the process of reducing methylene blue that is proportional to the number of living cells that depict cells viability. The $\mathrm{IC}_{50}$ value of HepG2 cells is $242.5837 \mu \mathrm{g} /$ $\mathrm{mL}$, whereas in WRL-68 is $285.2718 \mu \mathrm{g} / \mathrm{mL}$.

According to $\mathrm{IC}_{50}$ value, $\alpha$-mangosteen shows more toxic to liver cancer cells HepG2 compared to normal liver cells WRL-68. Figure 1. Liver cancer cells contain oxidative stress than those found in normal liver cells (Barrera, 2012). Treatment with $\alpha$-mangosteen added more antioxidant, hence it can inhibit the mechanism of free radical formation.

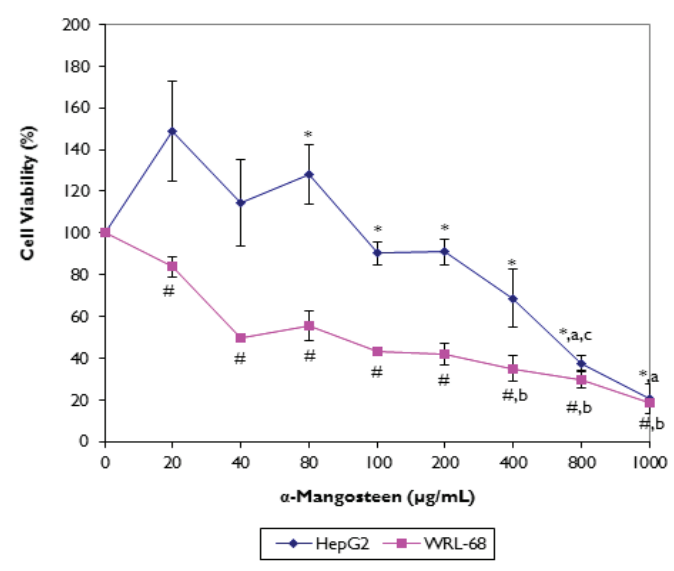

Figure 1. Cytotoxicity effect of a-Mangosteen on cancer cell (HepG2) and normal hepatocyte cells (WRL-68). The results are presented in the average values \pm standard deviations of three different repetitions in which each work is done triplicate.

A comparison cells treated with a-mangosteen from various concentrations and control $\left({ }^{*} p<0.05\right)$ in HepG2 cells and $(\# p<0.05)$ in normal hepatocyte cells (WRL-68).

a) Significantly difference compared to $40 \mu \mathrm{g} / \mathrm{mL}(p<0.01)$ in HepG2 cells

b) Significantly difference compared to $40 \mu \mathrm{g} / \mathrm{mL}(p<0.01)$ in WRL-68 cells

c) Significantly difference between HepG2 and WRL-68 cells at $800 \mathrm{ug} / \mathrm{mL}(p<0.05)$ 


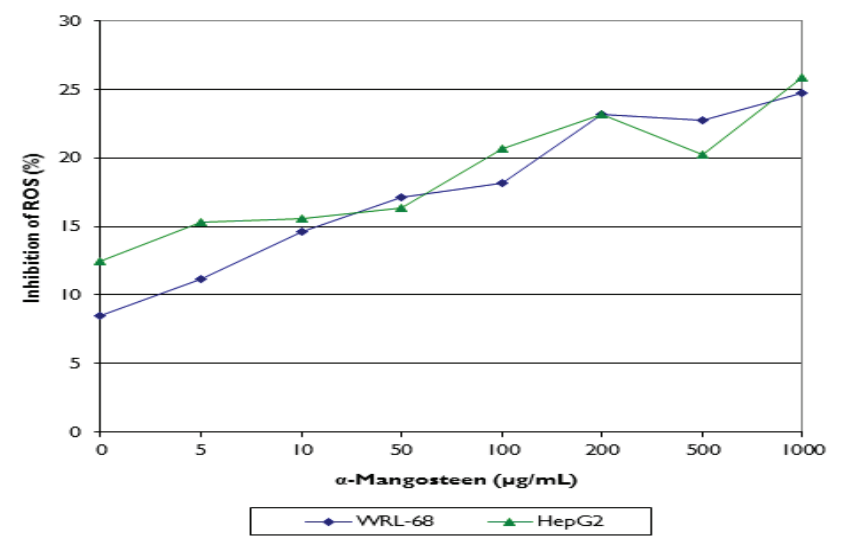

Figure 2. The Effect Inhibition of ROS of a-Mangosteen on in cancer cells (HepG2) and normal hepatocyte cells (WRL-68). The results indicated that a-mangosteen able to inhibit the formation of ROS within HepG2 cells under triplicate experiment. The concentration of $200 \mu \mathrm{g} / \mathrm{mL}$ a-mangosteen (concentration approaching $\mathrm{IC}_{50}$ value) was able to inhibit ROS formation in HepG2 was $23.15 \pm 4$. $3 \%$ compared to WRL-68 of $23.2 \pm 2.1 \%$.

\section{Cellular ROS Analysis}

The antioxidant properties contained in $\alpha$-mangosteen can eradicate free radical reactions through three mechanisms, namely (1) neutralization by antioxidant enzymes; (2) termination of the initial chain by antioxidants instead of enzymes; and (3) chain termination through binding to transition metal ions $(\mathrm{Cu} 2+, \mathrm{Fe} 2+)$ by plasma proteins.

Based on antioxidant properties, $\alpha$-mangosteen can be used as an anti-cancer compound to inhibit cell growth as cancer cells have high levels of oxidative stress. Therefore, giving antioxidants toward cancer cells can reduce oxidative stress. Antioxidant properties also induce apoptotic and regulate both of signal transduction molecules and cell redox molecules leading to inhibit cancer cells proliferation (Figure 2).

\section{Mangosteen Effect on Malondialdehyde (MDA) Levels of Cancer Cells}

The decline of MDA levels both in HepG2 and WRL-68 cells after treated with $\alpha$-mangosteen was not significant. Based on Figure 3, $\alpha$-mangosteen treatment more able to inhibit MDA formation in
HepG2 rather than in WRL-68 at the concentration above $500 \mu \mathrm{g} / \mathrm{mL}$. This is might be the oxidative stress level is higher in liver cancer cells than in normal cells. The $\alpha$-mangosteen exhibited more antioxidant properties causing inhibition of the free radicals' formation such as MDA which is the endproduct of lipid peroxidation.

The Levels of Protein Carbonyl (PC) of Cancer Cells Treated with a-Mangosteen

The formation of $\mathrm{PC}$ is able to inhibited by $\alpha$-mangosteen in HepG 2 cells. At a concentration $200 \mu \mathrm{g} / \mathrm{mL}$ of $\alpha$-mangosteen (concentration approaching $\mathrm{IC}_{50}$ value) was able to inhibit the PC formation in $\mathrm{HepG} 2$ cells of $79.84 \pm 5.1 \%$ compared to WRL-68 cells of $39.57 \pm 5.51 \%$.

\section{DISCUSSION}

Various kinds of xanthones in Garcinia mangostana L. have been proven for having a strong antioxidant feature including $\alpha$-mangosteen . The $\alpha$-mangosteen is a yellowish-compound which can be obtained from the other parts of the plant 


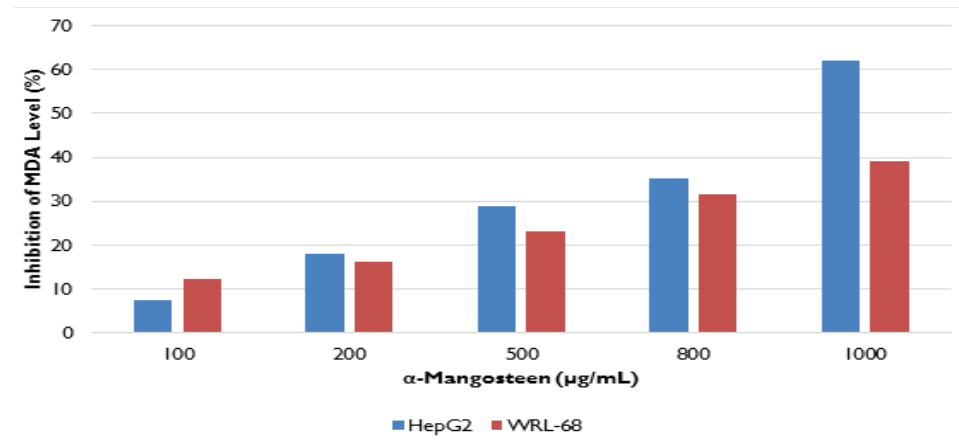

Figure 3. The MDA level of a-Mangosteen on cancer cells (HepG2) and normal hepatocyte cells (WRL-68).

as well, such as the dried sap and the bark. This compound has been discovered to possess a wide range of biological activities, such as antioxidant, anti-inflammatory, anti-tumor, and anti-bacterial and anti-obesity agents. The cytotoxic effects of $\alpha$-mangosteen in cancer cells (HepG2) and normal hepatocyte cells (WRL-68) were determined by MTT assay. The $\alpha$-mangosteen treatment showed dose-dependent toxicity toward HepG2 and WRL68 after $24 \mathrm{~h}$ incubation with $\mathrm{IC}_{50}$ values are 242.5837 and 242.5837 respectively. In the other hand, Manimekalai et al., 2016 stated the $\mathrm{IC}_{50}$ after treated with chloroform extract and hexane extract epicarp on HepG2 cells were $50 \mu \mathrm{M}$ and $5.25 \mu \mathrm{M}$ respectively. Adenina, et al., 2020 also stated the $\mathrm{IC}_{50}$ of $\alpha$-mangosteen was $23.74 \mu \mathrm{M}$ under MTS assay. The distinct result might be influenced by cells passage, treatment concentration, micronutrient factor, and redox properties within HepG2 cells (Adenina, et al., 2020).

ROS is constantly formed within cells and tissues that can be prevented by antioxidant defense system. The cellular antioxidant properties of mangosteen disturbances free radical reactions in 5 ways, namely (1) inhibition of ROS formation; (2) termination of the initial ROS chain and its precursors; (3) chain termination through binding to transition metal ions $(\mathrm{Cu} 2+, \mathrm{Fe} 2+)$ by plasma proteins (4) up-regulation of the antioxidant enzyme system; and (5) maintain thiol group (-SH) from oxidizing (He, et al., 2017). Oxidative disruption of enzymes and protein structure exhibits progression of the disease. Protein carbonyls formed by oxidation also serves as markers of oxidative

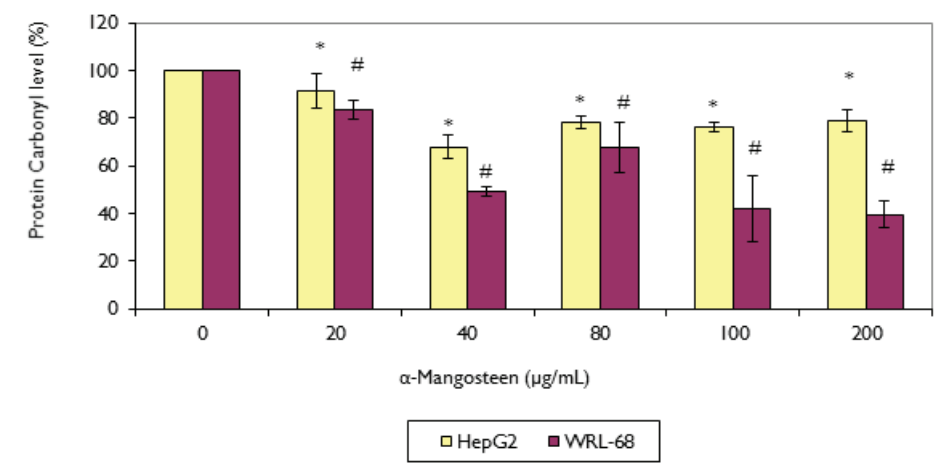

Figure 4. a-Mangosteen effect of carbonyl protein in cancer cells (HepG2) and normal hepatocyte cells (WRL-68). Statistically significant $\left({ }^{*} P<0.05\right)$ vs control in HepG2 and $(\# P<0.05)$ vs control in WRL-68. 
disruption within protein (Wong, et al., 2013). In this study, we analyzed ROS induction after treated with $\alpha$-mangosteen on HepG 2 cells through DCFDA assay. The result shows the increase of inhibition ROS levels after treated with $\alpha$-mangosteen on HepG2 cells in a dose-dependent trend. In addition, protein can also be interfered by massive reaction of ROS. Baek, et al. (2021) reported mangosteen at 2.5 and $10 \mu \mathrm{M}$ could reduce ROS levels in neuronal cells HT22 based on the DCFDA assay and reduce ROS as result of glutamate illustrated by fluorescents (Baek, et al., 2021).

The manifestations of oxidative stress are biomolecular impairment, induction of apoptosis, and tissue damage. The lipid peroxidation occurs due to accumulation of reactive electrophile species such as epoxide and aldehydes which malondialdehyde is the main product of lipid peroxidation. This hypothesis explained that the formation of MDA in vivo is a result of lipids oxidation from two or more double bonds. In addition, MDA formed through the byproducts of free radical formation due to ionization radiation and prostaglandin biosynthesis (Lykkesfeldt, 2007). MDA compounds can be mutagenic and carcinogenic which also can react with alkaline nitrogen from nucleic acid (DNA) at physiological $\mathrm{pH}$ to form $\mathrm{dG}, \mathrm{dA}$, and $\mathrm{dC}$. This form resembles the reaction of carbonyl groups with $\mathrm{N} 2$ and $\mathrm{N} 1$ from $\mathrm{dG}$ which losing water molecules $(\mathrm{H} 2 \mathrm{O})$ in order to produce pyrimidopurinon, M1G (Barrera, 2012). The result proves that $\alpha$-mangosteen-treated HepG2 cells could increase MDA levels in a dosedependent trend. MDA is the organic compound-end product of lipid peroxidation from polyunsaturated fatty acids that induces oxidative stress. In this study, the MDA level HepG2 and WRL-8 cells subjected with $\alpha$-mangosteen was evaluated. The result shows MDA level significantly increased in WRL-6 cells compared to HepG2 cells. This result indicated that the level of oxidative stress on liver cancer cells is higher than normal cells.

Among these reactions, carbonylation has attracted a great deal of attention due to its irreversible and unrepairable properties. Carbonylated proteins are marker of proteolysis which induced by the proteasome and the protease, but able to evade the degradation process and form a huge molecular aggregates that accumulated during aging. Several pathways of protein carbonylation are the conjugation with reactive carbonyl species and direct metal-catalyzed oxidative attack on amino acid residues. Protein carbonylation might contribute on organelle-specific signals formation and protein condition. The subsequent oxidative stress not only causes cell damage but also contributes lipids and proteins oxidation, including protein carbonylation. Alter of protein carbonyl formation correlated with free radicals production within HepG2 cells (Chienwichai, et al., 2019).

According to antioxidant properties of mangosteen, it can also be used as an anti-cancer agent to inhibit cancer cell growth as cancer cells contain high oxidative stress.. Therefore, giving antioxidants to cancer cells can reduce oxidative stress occurrence. The antioxidant activity of mangosteen can also be used as apoptosis inducer. Moreover, antioxidants are also able to regulate signal transduction molecules such as Bax, Caspase 8, Caspase 3, Nfא $\beta$ transcription factors, and cell redox molecules such as NADH, Glutathione which induce apoptosis to halt cancer cell proliferation (Cazzaniga \& Bonanni, 2012).

\section{CONCLUSION}

From this study can be concluded that $\alpha$-mangosteen reduced ROS levels, MDA and PC both in HepG2 and WRL-68 cells. Thus, $\alpha$-mangosteen is a potential anti cancer agent through inhibition of oxidative stress.

\section{REFERENCES}

Adenina, S., Louisa, M., Soetikno, V., Arozal, W. and Wanandi, S.I., 2020, The Effect of Alpha Mangostin on Epithelial-Mesenchymal Transition on Human Hepatocellular Carcinoma HepG2 
Cells Surviving Sorafenib via TGF-B/Smad Pathways, Advance Pharmaceutical Bulletin, 10(4), 648-655.

Baek, J.Y., Jung, K., Kim, Y.M., Kim, H.Y., Kang, K.S. and Chin, Y.W., 2021, Protective Effect of $\gamma$-mangostin Isolated from the Peel of Garcinia mangostana against Glutamate-Induced Cytotoxicity in HT22 Hippocampal Neuronal Cells, Biomolecules, 11(2), 170.

Barrera, G., 2012, Oxidative stress and lipid peroxidation products in cancer progression and therapy, International Scholarly Research Notices Oncology, 2012, 137289.

Bose, S., Banerjee, S., Mondal, A., Chakraborty, U., Pumarol, J., Croley, C.R. and Bishayee, A., 2020, Targeting the JAK/STAT Signaling Pathway Using Phytocompounds for Cancer Prevention and Therapy, Cells, 9(6), 1451.

Cazzaniga, M. and Bonanni, B., 2012, Breast Cancer Chemoprevention: Old and New Approaches, Journal of Biomedicine and Biotechnology, 2012, 985620.

Chienwichai, P., Reamtong, O., Boonyuen, U., Trairak Pisitkun, T., Somparn, P., Tharnpoophasiam, P., Worakhunpiset, S. and Topanurak, S., 2019, Hepatic protein Carbonylation profiles induced by lipid accumulation and oxidative stress for investigating cellular response to non-alcoholic fatty liver disease in vitro, Proteome Science, $17,1$.

Elmund, B. and Hartrianti, P., 2020, Evaluation of mangosteen (Garcinia mangostana) antioxidant activity in clinical trials and in vivo animal studies: A systematic review, Journal of Applied Pharmaceutical Science, 10(12), 114-129.

Gani, R.A., 2017, Hepatocellular Carcinoma (HCC) Surveillance-Comprehensive Management in Liver Cirrhosis Patients, The Indonesian Journal of Gastroenterology, Hepatology and Digestive Endoscopy, 18(3), 137-139.

Ghouri, Y.A., Mian, I. and Rowe, J.H., 2017, Review of hepatocellular carcinoma: Epidemiology, etiology, and carcinogenesis, Journal of carcinogenesis, 16, 1.
He, L., He, T., Farrar, S., Ji, L., Liu, T. and Ma, X., 2017, Antioxidants Maintain Cellular Redox Homeostasis by Elimination of Reactive Oxygen Species, Cellular Physiology and Biochemistry, 44(2), 532-553.

Jasirwan, C.O.M., Hasan, I., Sulaiman, A.S., Lesmana, C.R.A., Kurniawan, J., Kalista, K.M., Nababan, S.H. and Gani, R.A., 2020, Risk factors of mortality in the patients with hepatocellular carcinoma: A multicenter study in Indonesia, Current Problems in Cancer, 44(1).

Liguori, I., Russo, G., Curcio, F., Bulli, G., Aran, L., Della-Morte, D., Gargiulo, G., Testa, G., Cacciatore, F., Bonaduce, D. and Abete, P., 2018, Oxidative stress, aging, and diseases, Clinical Interventions Aging, 13, 757-772.

Lykkesfeldt, J., 2007, Malondialdehyde as biomarker of oxidative damage to lipids caused by smoking, Clinica Chimica Acta, 380(1-2), 50-58.

Selvaraj R, Kanakarazan, S. and Kamalanathan, A., 2016, Antioxidant and anticancer potential of mangosteen fruit, garcinia mangostana against hepatocellular carcinoma (HEPG-2) cell line, World Journal of Pharmacy and Pharmaceutical Sciences, 5(2), 253-293.

Le Grazie, M., Biagini, M.R., Tarocchi, M., Polvani, S. and Galli, A., 2017, Chemotherapy for hepatocellular carcinoma: The present and the future, World Journal Hepatolology, 9(21), 907-920.

Quan, X., Wang, Y., Ma, X., Liang, Y., Tian, W., Ma, Q., Jiang, H. and Zhao, Y., 2012, a-Mangostin induces apoptosis and suppresses differentiation of 3T3-L1 cells via inhibiting fatty acid synthase, PLoS ONE, 7(3), e33376:1-10.

Tan, A.C., Konczak, I., Sze, D.M. and Ramzan, I., 2011, Molecular pathways for cancer chemoprevention by dietary phytochemicals, Nutrition and cancer, 63(4), 495-505.

Wong, C-M., Marcocci, L., Das, D., Wang, X., Luo, H., Zungu-Edmondson, M. and Suzuki, Y.J., 2013, Mechanism of protein decarbonylation, Free Radical Biology \& Medicine, 65, 1126-1133. 